\title{
Benchmarking avi-tourism literacy rates among Gauteng school learners
}

\author{
D.H. Tustin ${ }^{a}$ and N. Conradie ${ }^{b}$

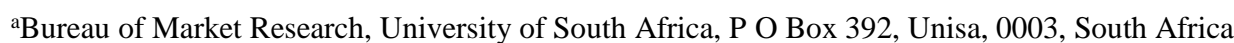 \\ bepartment of Transport Economics, Logistics and Tourism, University of South Africa \\ *To whom all correspondence should be addressed \\ tustidh@unisa.ac.za
}

\begin{abstract}
Literacy on birds and the natural environment among young citizens is critical in addressing current and emerging environmental challenges. To improve the future awareness, involvement, knowledge, values and pro-environmental behaviour of young South Africans towards birds, the natural habitat of birds and avi-tourism, this article benchmarks avitourism literacy rates among secondary school learners. The study arrived at an avi-tourism literacy rate of $43.66 \%$ which presupposes passive behaviour of learners towards birds, bird habitat and avi-tourism activities. Besides lacking basic bird and environmental knowledge, learners have also not yet reached the desired levels of emotional affection towards birds and the natural environment. However, increased awareness and affinity, involvement, values and behavioural intention will most likely entice pro-avi and environmental behaviour. The research poses clear challenges to professionals and educators within the tourism industry of South Africa to increase learners' willingness and motivation to act proenvironmentally through dedicated education. This supports the need to introduce an intervention programme in order to promote awareness, knowledge, values and pro-avi and environmental behaviour among learners.
\end{abstract}

\section{Introduction}

In South Africa, the tourism industry is considered a priority sector due to its potential to contribute significantly to sustainable economic, social and environmental wellbeing of all citizens of the country. As South Africa has a remarkable wealth of birdlife and because birding is one of the fastest growing hobbies around the world, avi-tourism (birding tourism) is recognised as an important niche market with economic value and significant growth potential (Biggs Turpie, Fabricius \& Spenceley, 2011:87; DoT, 2011b:12). The National Avi-tourism Strategy of South Africa sets out the country's vision of 'positioning South Africa as a globally competitive avi-tourism destination' (DoT, 2011b:12). This strategy suggests that sustainable avi-tourism is dependent upon the natural resource base, specifically birds and their native habitat. Therefore, to realise the potential of sustainable avi-tourism in South Africa now and in the future, the protection and conservation of birds and their natural habitat are imperative.

However, the potential of avi-tourism to contribute significantly to sustainable growth in South Africa is adversely affected in an alarming accelerating rate by the detrimental effects of climate change, environmental degradation and biodiversity loss. Birds play an integral role in biodiversity, yet the numbers of certain species are decreasing at a rapid rate in all parts of the world (McColaugh, 2007:8). The key role of education that will encourage changes in values, mind sets and behaviour with regards to the sustainability problems relating to environmental degradation is highlighted in various scientific publications (for example, Bramwell \& Lane, 2013). Changing environmental behaviours, such as recycling, litter and energy use and encouraging environmental citizenship require active participation of citizens and a firm understanding of what works in terms of educational programmes or interventions aimed at behavioural change (Goodwin, Greasley, John \& Richardson, 2010). One approach to promote pro-environmentalism over the longterm is to improve the environmental attitudes and behaviour of young people (Goodwin et al., 2010). The current day learners will have a major influence on the future state of the natural environment (including birds and bird habitat) which makes innovative ways of interactive learning and engagement at school level on environmental sustainability highly relevant.

This study was designed on the premises that pro-avi (bird) and environmental behaviour of young people will set a sound basis for sustainable avi-tourism being regarded as a key potential growth area of future ecotourism in South Africa. The development of sustainable avi-tourism via sustainable avi-tourism intervention programmes is likewise anticipated to improve the economic, social and environmental sustainability of the South Africa. However, before an educational strategy or intervention programme that improve attitudes and behaviour towards birds and the natural environment can be developed, an understanding of the current level of education or literacy of young people on birds, the natural habitat of birds and avi-tourism activities was needed. The focus of this research is therefore to determine the current awareness and affinity, involvement, knowledge, values and environmental behaviour of young people towards birds and their natural habitat. In this article, these constructs are collectively considered as 'avi-tourism literacy'. 


\section{Aim}

The aim of this article was to benchmark avi-tourism literacy rates among secondary school learners with the intention to improve the future awareness, attitudes, values and proenvironmental behaviour of young South Africans towards birds, the natural habitat of birds and avi-tourism. To achieve this aim, four research questions were identified: a) What is the current level of avi-tourism literacy of secondary school learners in the Gauteng Province on specific avi-tourism literacy constructs (awareness and affinity, involvement, knowledge, values and environmental behaviour)? b) What is the current avi-tourism literacy rate of secondary school learners in the Gauteng Province? c) Are there differences between gender and age groups on the identified avi-tourism literacy constructs? and d) Are there significant relationships between the identified avi-tourism literacy constructs?

To address these research questions, a self-administered questionnaire was developed to measure the awareness and affinity, involvement, knowledge, values and behaviour of secondary school learners towards birds and their natural habitat. Data were collected at two secondary schools in the Gauteng Province (South Africa) in 2014. A fairly young population segment (13 to 16 year olds) was specifically targeted to consider the need for intervention programmes aimed at secondary schools. Also, the study concentrates on secondary school level to raise the interest of teachers and school learners in gaining literacy about birds and their role in maintaining biodiversity.

Using descriptive statistics, the constructs measured in the questionnaire were combined to establish a benchmark for avi-tourism literacy of secondary school learners in Gauteng. Furthermore, a correlation analysis was employed to determine the linear relationships between the constructs measuring avi-tourism literacy.

The article commences with the research method applied followed by the results of the pilot study. In the results section, the constructs are briefly discussed and the findings are structured according to the four research questions. The outcome of the pilot study and recommendations are reported in the conclusion.

\section{Key concepts}

Sustainable tourism is defined as 'tourism which is economically viable but does not destroy the resources on which the future tourism will depend, notably the physical environment and the social fabric of the host community' (Swarbrooke, 1999).

Pro-environmental behaviour' is defined as behaviour that consciously seeks to minimise the negative impact of learner's actions on the natural and built world (for example, minimise resource and energy consumption that will support the existence of birds, reduce waste production to protect and save birds). Sivek and Hungerford (1989); (1990); Osbaldiston and Schott (2012) also define pro-environmental behaviour as the action of an individual or group that advocates the sustainable or diminished use of natural resources.

Avi-tourism refers to "travel by bird-watchers, domestically and internationally, outside of one's usual environment, for the purpose of viewing birds in their natural habitat". Avitourism is centred on components of the natural environment, that is, birds and their habitat, and is therefore a sub-category of nature-based tourism (DoT, 2011).

Avi-tourists refer to "people who travel to view birds in their natural habitats" (DoT, 2011).

Avi-tourism literacy rates refer to the percentage of learners with awareness and affinity, involvement, knowledge, positive value sets and pro-environmental behaviour traits towards birds, the natural habitat of birds and avi-tourism activities (author definition).

\section{Methodology}

\section{Research design and method}

A survey-based research design was used to obtain primary data for this pilot study. The data for the study were collected by means of self-administered questionnaires that were distributed to the research population, comprising secondary school learners in Grades 8 to 10. The questionnaire for the pilot study included six major constructs and 107 variables measuring awareness and affinity, involvement, basic knowledge, values and intended and actual behaviour of learners in birds and their natural environment. Collectively, these constructs were used to measure avi-tourism literacy. Table 1 summarises the number of constructs and variables included in the research model.

\section{Table 1: Research constructs and variables}

\begin{tabular}{l|r}
\hline \multicolumn{1}{c|}{ Constructs } & No of variables \\
\hline Awareness and affinity & 14 \\
\hline Involvement & 11 \\
\hline Basic knowledge & 29 \\
\hline Values & 20 \\
\hline Intended behaviour & 19 \\
\hline Actual behaviour & 14 \\
\hline Total & 107 \\
\hline
\end{tabular}

\section{Awareness and affinity}

Awareness is described as holding a general impression, or consciousness about something (Elder, 2003). For the purpose of this study, the avi-awareness scale reflects a general impression, or consciousness about the general importance and sustainability of birds and their natural habitat (Larson, Green \& Castleberry, 2011). In turn, affinity can be described as a natural inclination or attraction to something while avi-affinity reflects personal interest in birds and their natural habitat (Larson et al., 2011). Interest in its simplest form is something that people enjoy learning about or doing. For this study, birding interest was defined 
as a feeling of wanting to learn more about bird species, natural bird habitats and the ecological significance of birds and/or to be directly involved in bird watching/birding.

With reference to avi-awareness and avi-affinity, students were firstly requested to score 14 agreement statements. The proportion of learners who assertively displayed awareness of and affinity towards birds and their natural habitat ranged between $15.0 \%$ for the likelihood to read about birds to $66.6 \%$ for the need to take care of bird habitats. The findings also displayed fairly high levels of affection among learners towards birding and their natural environment. In fact, at least six in every ten learners are most compassionate about birds $(64.44 \%)$ and their habitats $(66.62 \%)$. However, these positive feelings have clearly not transcended into the desire to improve comprehension levels regarding birds and their natural habitats. In this regard, only $14.99 \%$ and $29.02 \%$ of the learners agreed that they enjoy reading about birds and learning about natural bird habitats respectively. Even when it comes to personal sacrifices, it is only one in every three learners $(30.79 \%)$ who seems willing to give-up own money to save birds. The overall avi-awareness and avi-affinity score of $38.30 \%$ is rather gloomy and poses clear challenges to transform the noteworthy emotional interest of learners towards birds and their habitat into more active interest.

\section{Involvement}

In general, involvement refers to the level of perceived personal importance and/or interest evoked by a stimulus (or stimuli) within a specific situation (Antil, 1984:204; Kotler \& Keller, 2009:214). More specifically, involvement in the context of leisure is described by measures such as ability or skill, number of memberships, frequency of participation, money or time spent, equipment owned, miles travelled and experience (Havitz \& Dimanche, 1990:184; Kim, Scott \& Crompton, 1997). A person's degree of involvement can be conceived as a continuum, ranging from absolute lack of interest at the one end to obsession at the other. Thus, novice birders would participate infrequently with a variety of motivations, whereas advanced birders would participate more frequently with more specific motivations (Solomon, Bamossy \& Askegaard, 2002:104).

To measure learners' self-reported involvement in birdwatching, 11 binary questions were posted to learners. The results ranged between $2.5 \%$ of learners affirming membership of a birding club while $64.6 \%$ indicated that they feed birds. Only one in every three $(31.34 \%)$ indicated that they have hunted birds. The latter outcome reflects somewhat immature behaviour among one in every three learners. Also, the facts that participating learners mainly feed birds and only $2.45 \%$ of them proclaim to belong to a bird club best classifies them as passive birders (as opposed to active birders). This classification is further evident from the fact that only a third of learners' own a bird book $(34.33 \%)$ or ever used a bird list to identify birds $(31.34 \%)$, while only one in every five learners $(19.07 \%)$ already attended a bird course. Almost half $(45.05 \%)$ of learners have listened to bird sounds via a cellphone application but only a quarter (23.98\%) actually downloaded such application. Furthermore, more learners $(40.05 \%)$ have participated in family trips to watch birds than participating in field/school trips $(31.88 \%)$. Collectively, the analysis on the involvement in birding by secondary school learners shows a fairly passive involvement rate of $36.78 \%$.

\section{Basic knowledge of birds and the environment}

Developing environmental knowledge requires more than a general awareness or consciousness of the environment. It requires an understanding and comprehension of human and natural systems and processes (Elder, 2003). One of the major objectives of environmental education is the acquisition of environmental knowledge, which means 'to help social groups and individuals gain a variety of experience in, and acquire a basic understanding of the environment and its associated problems' (Leon, 2005). In this study, the basic knowledge of birds and their natural environment were investigated. More specifically, to test the basic knowledge of learners regarding birds, learners were firstly challenged to correctly identify bird family names. Considering the overall knowledge levels on a total of 29 items, participating learners scored a knowledge comprehension mark of $49.74 \%$. This assessment outcome shows average knowledge levels regarding birding and their habitat.

If young people are going to make informed decisions about the sustainability of birds and their natural habitat, then they must be equipped with a fundamental knowledge of birds and the natural environment as a whole. However, an increase in young people's knowledge about birds and the environment may raise peoples' concerns about birds and their natural environment, but it does not necessarily result in responsible environmental behaviour. These opinions are supported by Zsóka (2013) who advocates that "changes in environmental and avi-values are necessary drivers for environmental action and might influence pro-environmental behaviour."

\section{Environmental and avi-values}

Personal values are the principles, standards, qualities or beliefs that are important to people and influence and guide their behaviour. With specific reference to this study, values represent the unconditional likes and dislikes of learners or their concerns, beliefs and attitudes towards and relationship with birds and their environment. Environmental values in particular are regarded as crucial determinants of proenvironmental behaviour (Boeve-de Pauw \& Van Petegem, 2011). Therefore, the more strongly individuals subscribe to environmental values, the more likely they are to engage in pro-environmental behaviour (Steg \& Vlek, 2009). Consequently, the study was designed to specifically capture the emotional involvement of learners to determine the extent to which learners have an affective relationship to the natural bird environment. The rationale for including emotional connections is regarded as very important in shaping beliefs, values and attitudes towards the environment. Also, emotional involvement requires a certain degree of environmental knowledge and awareness. Against this background, the study included 20 environmental and avi- 
value statements which learners were requested to rate. The overall value score of $36.28 \%$ displayed that the environmental and avi-values measured by the pilot study have little significance to the majority of learners. Encouragingly, the research results show clear concerns among approximately half of the learners regarding the environment (living in harmony with nature to prevent the extinction of birds, $51.91 \%$; setting aside areas to protect endangered bird species, 50.82\%; solving environmental problems effecting birds, 51.91\%; and the protection of plants, birds and animals due to their economic importance). However, their interest in and enjoyment of birds (29.56\%) and protection of birds habitat via responsible environmental behaviour (saving water, 37.78\%; and electricity, 29.02\%) remain dismal.

\section{Behavioural intention}

Behavioural intention (BI) is defined as a person's perceived likelihood or subjective probability that he or she will engage in a given behaviour (Committee on Communication for Behaviour Change in the 21st Century, 2002:1). Ajzen (1991) argued that BI reflects how hard a person is willing to try, and how motivated he or she is, to perform the behaviour. To measure BI in avi-tourism, the study applied an environmental psychological approach whereby measures of pro-environmental behaviour were based on a list of 19 intended pro-environmental behaviours. More specifically, a semantic differential scale was used to measure learners' intended pro-avi- and environmental behaviours. These statements served as a proxy for learners' (i) willingness to try and (ii) motivation to act pro-environmentally. The findings showed that at most $60 \%$ of learners will be inclined to visit a local zoo to learn more about birds. Overall, only one in every two learners $(52.83 \%)$ intends to act proenvironmentally. Learners seem least interested to join a local bird-watching club $(40.05 \%)$ or talk to teachers about a bird club at school (52.23\%). Furthermore, only $45.78 \%$ learners are willing to adopt their buying behaviour to save birds. Overall, learners show a relatively average probability or likelihood to act pro-environmentally.

\section{Actual pro-avi- and environmental behaviour}

Pro-environmental behaviour is an approach used to help ameliorate environmental problems such as, climate change, conflicts over resources and pollution. Pro-environmental behaviours are described as an attempt to influence an individual's behaviour to act in a more environmentally friendly or environmentally sustainable manner. Therefore, individuals are encouraged to adopt behaviours that are comparatively better for the environment (Osbaldiston \& Schott, 2012). To measure the actual pro-environmental behaviour of learners, a series of 14 statements promoting pro-environmental and avi-tourism behaviour were formulated. These statements featured avi-tourism facets that provide environmental benefits to communities and help to educate learners about the value of birds and biodiversity as well as the protection and preservation of bird's natural habitat. More specifically, the series of statements intended to identify the prevalence of 'avi-tourists' or 'birders' among learners who supposedly should be well-educated, have high levels of ecological knowledge and greater awareness of bird conservation issues. Finally, the impactoriented focus adopted by the study on the actual environmental impact of learner behaviours enabled the identification of targeted behaviours among learners that significantly influence the environment in which birds live.

Against this background, the study confirmed the gap existing between intended and actual behaviour. Whereas just more than half of the learners showcased 'good' intentions to participate in pro-avi and environment behaviour and avitourism activities, only a third (37.36\%) showcased selfreported actual participation. This finding showcases that learners are rather passive with regard to responsible environmental behaviour, and that their participation in birdwatching activities is rather low. In fact, only a few learners have talked to teachers or parents about pollution (32.15\%), how to limit environmental problems that affect bird habitats $(32.77 \%)$, and only four out of 10 learners do not dispose of garbage while driving (43.32\%). Furthermore, approximately a third of learners are not inclined to read about birds $(30.79 \%)$ nor undertake birding trips to museums $(32.70 \%)$, nature reserves $(34.06 \%)$ or the zoo $(39.51 \%)$.

\section{Avi-tourism literacy rates by construct}

Figure 1 provides a consolidated analysis of the six constructs investigated in the study. In fact, as explained, these constructs collectively combine to describe 'avi-tourism literacy'.

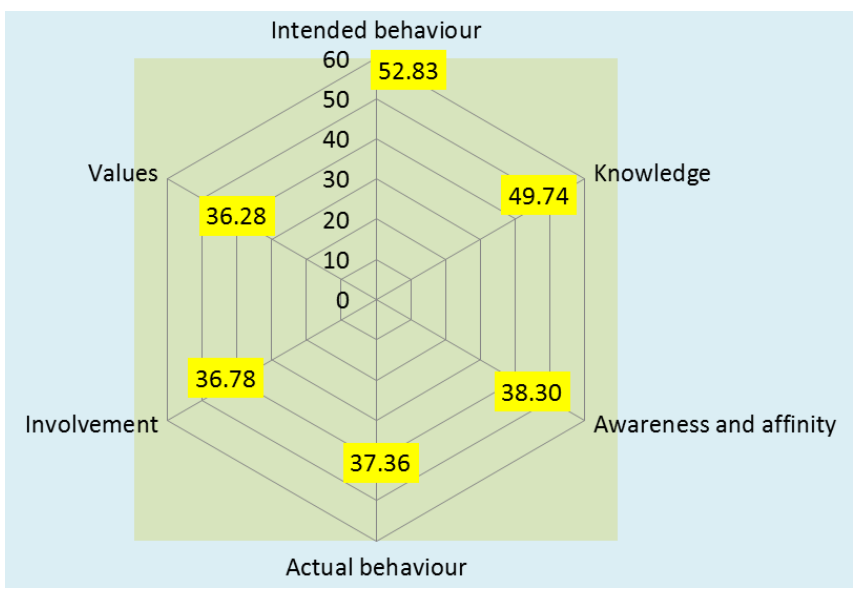

\section{Figure 1: Avi-tourism literacy rates by construct}

The information outlined in figure 1 clearly shows that the intended behaviour (BI) of learners has not culminated into the same magnitude of interest (awareness and affinity, $38.30 \%)$ and value $(36.28 \%)$ attached to birds, birding and the natural habitat of birds. Consequently, the involvement $(36.78 \%)$ and actual pro-avi and environmental behaviour $(37.36 \%)$ are evident among only one in three learners. Also, the study of basic bird knowledge (claimed by approximately $50 \%$ of learners) does not congruently result into actual behaviour and involvement in bird live and birding. When 
consolidating the six construct scores, the study finally arrived at an avi-tourism literacy rate of $43.66 \%$. This score presupposes that the learners who participated in the pilot study can at best be described as having passive behaviour towards the environment, birds and their habitat and therefore avi-tourism activities.

The fairly low avi-tourism literacy rates among secondary school learners indicate a need to considering future strategies that will improve this score. In the next section, avitourism literacy rates are therefore compared between the learner's gender and school grade to investigate differences between gender and age.

\section{Avi-tourism literacy rates by gender and school grade}

With the aim of considering future strategies to entice proenvironmental birding behaviour between different gender and age (with school grade used as proxy) cohorts, figures 2 and 3 provide comparative avi-tourism literacy rates. Figure 2 indicates no conspicuous differences between boys and girls on all constructs as well as the overall avi-tourism literacy rate. The same tendency was found among the different school grades (figure 3). Both figures 2 and 3 shows that the constructs, knowledge and intended behaviour of boys and girls and all three school grades measured are rather average; while the other constructs (awareness and affinity, involvement, values and actual behaviour) are on the low side. This result implies that, regardless of gender and age, learners' average bird and environmental knowledge has resulted in an average probability or intention to act proenvironmentally to save birds and their natural habitat. However, the results indicate that learners have not yet reached the desired levels of emotional affection towards birds and the natural environment. This finding suggests the development of affinity towards birds and avi-values as key foundations of enhanced avi and pro-environmental behaviour. Furthermore, a strategy that will enhance the avitourism literacy rate should prioritise awareness and affinity, involvement and values attached to birds and the natural environment in its design. The next section was included to determine if any significant relationships between the various avi-tourism constructs exist.

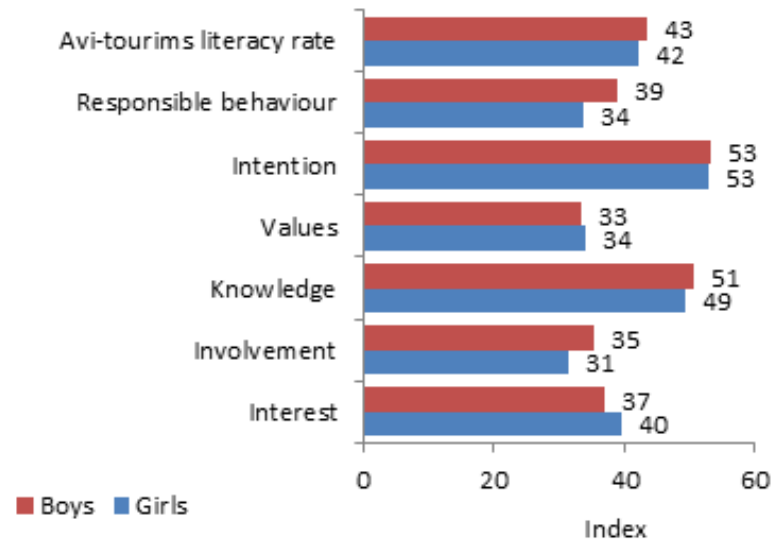

Figure 2: Avi-tourism literacy rates by gender

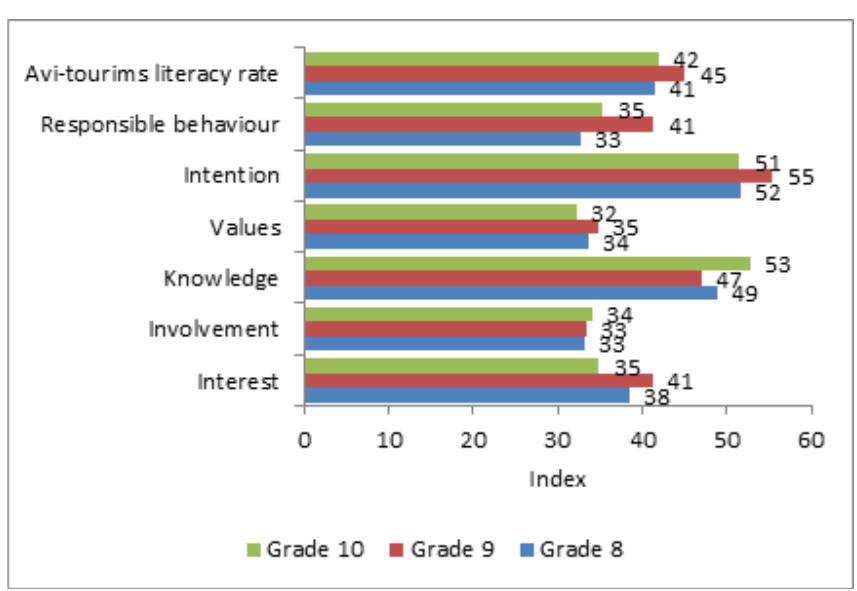

Figure 3: Avi-tourism literacy rates by school grade

\section{Correlations between constructs}

The Pearson product-moment correlation analysis was performed to determine the strengths of the association between the various constructs (Salkind, 2012). The outcome of this analysis revealed that a positive orientation towards birds and their natural habitat (awareness and affinity) will increase the learners' values $(r=0.633)$ and intentions to act positively towards birds and the environment $(\mathrm{r}=0.656)$. Involvement in the birding activity (for example, participating in a bird watching trip, owning a bird book or feeding birds) could result in developing affinity towards birds $(r=0.286)$ and increase responsible behaviour towards birds. Furthermore, a strong relationship exist between values and behaviour intention $(\mathrm{r}=0.588)$. The development of environmental and avi-values will therefore most likely increase learners' behavioural intent to act responsibly towards the environment. Behavioural intention is strongly related to awareness and affinity $(r=0.656)$; values $(r=$ $0.588)$ and responsible behaviour $(r=0.625)$. Furthermore, the results suggest that behavioural intention is the best predictor of responsible behaviour. Overall, the Pearson product-moment correlation matrix analysis shows positive correlation coefficients (linear associations) between the avitourism literacy constructs. Confirmation of the direct relationships and statistically significant correlations $(\mathrm{p}<$ 0.01 ) between all constructs supports the view advocated by this article that increased awareness and affinity, involvement, values and behavioural intention will most likely entice learners to behave more responsibly towards birds and their habitat. Knowledge dissemination is also most likely to induce values (although a weaker relationship; $r=$ 0.280 ) that could in turn transcend into actual responsible behaviour ( $r=0.399)$. Whereas stronger relationships exist between responsible behaviour and the compassion for and commitment towards birds and their habitat, growth in bird knowledge are stronger linked to learners' values towards birds and their habitat. 


\section{Discussion and recommendations}

The outcome of the pilot study can best be summarised as follows:

- Fairly high levels of affection (affinity) are discernible among learners towards birding and their natural environment. However, these positive sentiments have clearly not transcended into the desire to improve comprehension levels regarding birds and their natural habitats.

- The overall avi-awareness and avi-affinity of learners towards birds and their natural habitat are rather gloomy and poses clear challenges to transform the noteworthy emotional interest of learners towards birds and their natural habitat into more active interest.

- Learners possess average knowledge levels regarding birding and their natural habitat.

- Environmental and avi-values have little significance to the majority of learners.

- The interest in and enjoyment of birds and protection of bird habitats via responsible environmental behaviour (saving water and electricity) remain dismal among learners.

- Learners show a poor willingness, motivation or likelihood to act pro-environmentally.

- Learners' intended and actual pro-environmental behaviour differs significantly.

- Learners show a relatively low inclination to read about birds or to undertake birding trips.

- The overall avi-tourism literacy rate of $43.66 \%$ indicate a fairly passive behaviour towards birds, bird habitat and avi-tourism activities.

The summary of findings shows that environmental educators need to improve awareness and the understanding of the value of birds and the environment to learners. Finding effective ways to influence relatively low avi-tourism literacy levels and to increase learners' willingness and motivation to act pro-environmentally through education is thus indisputable. An important outcome of this research is therefore the need to introduce an intervention programme in order to promote awareness, knowledge, values and pro-avi and environmental behaviour among learners. Such an intervention programme could empower young people within an educational environment to improve their knowledge on avi-tourism and likewise improve their literacy levels and responsible behaviour in support of future sustainability of birds and their natural habitat. Against this background, the following recommendations suffice:

- To raise awareness of birds and bird habitat through attending bird-related events, such as the annual bird fair that is held by BirdLife ${ }^{\circledR}$ South Africa (the local conservation and birding NGO in South Africa), or visiting the National Zoological or Botanical Gardens, or conducting a tour in a nature reserve;

- Improve the involvement of learners by encouraging them to (i) become a member of a bird club, (ii) attend a bird course and (iii) uploading applications about birds on cellular phones;

- Improve learner interest in birds and birding by encouraging learners to (i) read more about birds and (ii) to learn more about different bird species;

- Improve pro-avi behaviour of learners by starting a birdwatching club at school;

- Increase environmental value sets of learners regarding birding and the natural habitat of birds by specifically focusing on issues such as pollution, destruction of natural habitat (road developments that destroy natural bird habitats) and the self-restoring of nature.

- Increase values and pro-avi behaviour by encouraging learners to spend time outdoors. According to Stevenson, Peterson, Bondell, Mertig and Moore (2013), outdoor activities have been linked to affective components and were found to be a key predictor of pro-environmental behaviour.

\section{Conclusion}

To realise the potential of sustainable avi-tourism in South Africa now and in the future, the protection and conservation of birds and their natural habitat are imperative. The current day learners will have a major influence on the future state of the natural environment (including birds and bird habitat) and therefore the sustainability of avi-tourism in South Africa. Therefore, this article highlights the importance of relevant education that will encourage changes in values, mind sets and behaviour with regards to the sustainability birds and the natural environment in which birds live. Therefore, the aim of this article was to benchmark avi-tourism literacy rates among secondary school learners with the intention to improve the future awareness, attitudes, values and proenvironmental behaviour of young South Africans towards birds, the natural habitat of birds and avi-tourism.

Based on results obtained from questionnaires completed by secondary school learners in the Gauteng Province, this article focused on addressing four research questions and arrived at the following main findings:

- The current level avi-tourism literacy on the constructs knowledge and intended behaviour are rather average; while the other constructs (awareness and affinity, involvement, values and actual behaviour) are on the low side.

- The overall avi-tourism literacy rate of $43.66 \%$ indicates a fairly passive behaviour of learners towards birds, bird habitat and avi-tourism activities.

- The results indicate no significant differences between gender and school grade on all constructs as well as the overall avi-tourism literacy rate.

- The correlation analysis indicates direct relationships and statistically significant correlations between all constructs supporting the view advocated by this article that increased awareness and affinity, involvement, values and behavioural intention will most likely entice learners to behave more responsibly towards birds and their habitat. 
Based on the relative low avi-tourism literacy rates, an intervention programme to promote awareness, knowledge, values and pro-avi and environmental behaviour among learners is suggested. Such an intervention programme could empower young people within an educational environment to improve avi-tourism literacy levels and likewise improve their and responsible behaviour in support of future sustainability of birds and their natural habitat.

There is a need to guide and develop young people to change their interest, value and pro-environmental behaviour regarding birds and bird habitat and avi-tourism. Therefore, it is recommended that environmental educators should realise the importance to create awareness of birds since childhood. Further practices that could support this recommendation could include the encouragements of young people to frequently undertake birding trips, attend courses and invest in bird watching equipment (for example, binoculars, cameras and audio equipment in order to identify and/or capture images and sounds of birds). These actions will ultimately create a love for birds and nature as a whole and motivate young people to love, conserve and sustain birdlife over a lifetime. Children of today are tomorrow's public leaders, business operators and tourists.

\section{References}

Ajzen, I. 1991. 'The theory of planned behaviour', Organizational Behaviour and Human Decision Processes, 50: 179-211.

Antil, J.H. 1984. 'Conceptualization and operationalization of involvement', Advances in consumer research, 11: 203-209.

Biggs, D., Turpie, J., Fabricius, C. \& Spenceley, A. 2011. 'The value of avi-tourism for conservation and job creation - An analysis from South Africa', Conservation and Society, 9(1): 80-90.

Bramwell, B. \& Lane, B. 2013. 'Getting from here to there: Systems change, behavioural change and sustainable tourism', Journal of Sustainable Tourism, 21(1): 1-4.

Committee on communication for behaviour change in the $21 \mathrm{st}$ century. 2002. Speaking of health: Assessing health communication strategies for diverse populations. Washington, DC: National Academies Press.

DoT (Department of Tourism). 2011. National tourism sector strategy. Pretoria: DoT.

Elder, J.L. 2003. A field guide to environmental literacy: making strategic investments in environmental education. Manchester, MA: Environmental Education Coalition.

Goodwin, M.J., Greasley, S., John, P. \& Richardson, L. 2010. 'Can we make environmental citezens? A randomised control trail of the effects of a school-based intervention on the attitudes and knowledge of young people', Environmental Politics, 19(3): 392412.

Havitz, M.E. \& Dimanche, F. 1990. 'Propositions for testing the involvement construct in recreational and tourism contexts', Leisure Sciences: An Interdisciplinary Journal, 12(2): 179.

Kim, S., Scott, D. \& Crompton, J.L. 1997. 'An exploration of the relationships among social psychological involvement, behavioural involvement, commitment, and future intentions in the context of birdwatching', Journal of Leisure Research, 29(3): 320-341.

Kotler, P. \& Keller, K.L. 2009. Marketing management. International Edition. New Jersey: Pearson Prentice-Hall.

Larson, L.R., Green, G.T. \& Castleberry, 2011. 'Construction and validation of an instrument to measure environmental orientations in a diverse group of children', Environment and Behaviour, 43(1): 7289.

Leon, M.J. 2005. Readings in environmental education: An urban model. Iowa: Kendall/Hunt Publishing Company.

McColaugh, D. 2007. Bird activity book. Gaborone: Printing and Publishing Company Botswana.

Osbaldiston, R. \& Schott, J.P. 2012. 'Environmental sustainability and behavioural science: Meta-analysis of pro-environmental behaviour experiments', Environment and Behaviour: 44(2): 257299.

Boeve-de Pauw, J. \& Van Petegem, P. 2011. 'A cross-cultural study of environmental values and their effect on the environmental behaviour of children', Environment and Behaviour, 45(5): 551583.

Salkind, N. J. 2012. Exploring research. 2nd Edition. Salt River, NJ: Pearson.

Sivek, D.J. \& Hungerford, H. 1989/1990. 'Predictors of responsible behaviour in members of Wisconsin conservation organizations', The Journal of Environmental Education, 21(2): 35-40.

Solomon, M.R., Bamossy, G. \& Askegaard, S. 2002. Consumer behaviour: A European perspective. 2nd Edition. England; New York: Financial Times/Prentice-Hall.

Steg, L. \& Vlek, C. 2009. 'Encouraging pro-environmental behaviour: An integrative review and research agenda', Journal of Environmental Psychology, 29: 309-317.

Stevenson, K.T., Peterson, M.N., Bondell, H.D., Mertig, A.G. \& Moore, S.E. 2013. 'Environmental, institutional, and demographic predictors of environmental literacy among middle school children', PLOS ONE, 8(3): 1-5.

Zsóka, A., Szerényi, Z. M., Széchy, A. \& Kocsis, T. 2013. 'Greening due to environmental education? Environmental knowledge, attitudes, consumer behaviour and everyday pro-environmental activities of Hungarian high school and university students', Journal of Cleaner Production, 48: 126-138. 